\title{
Crescimento, câmbio e importações no Brasil e Paraná
}

Claudia Lacerda Martins*

Luciano Nakabashi*

RESUMO - Este artigo trata da evolução das importações nas esferas nacional e estadual (Paraná), formando uma interligação com as alterações sentidas nos últimos dez anos das atividades produtivas desenvolvidas em ambas as esferas. Para tanto além da análise da evolução quanto a composição geral, é apresentada a análise desagregada das variações dos itens que compõe ambas as pautas e seus movimentos ao longo do período estudado, os quais estão diretamente ligados as variações cambiais.

Palavras-chave: Importações. Crescimento. Câmbio.

\section{INTRODUÇÃO}

A evolução do roll das importações brasileira, para as quais historicamente há uma predominância dos bens manufaturados, vislumbrou recentemente o crescimento da demanda por insumos energéticos e químicos, os quais tencionam refletir o recente processo de crescimento econômico do país. Este movimento encontra, no estado do Paraná, algumas distinções em relação ao caso brasileiro, sendo as mesmas paradoxais.

Por um lado o estado reduziu sensivelmente alguns dos itens importados relacionado ao setor automotivo, isto ocorreu tanto para os itens intermediários bem como para o produto final, ou seja, o automóvel em si, numa proporção maior. Na outra mão torna-se perceptível uma acentuação da pauta de insumos/produtos ligados ao setor agroexportador (fertilizantes), que é o "carro chefe" da economia do estado. Todavia apesar destas alterações mantém-se a característica geral, a mesma apontada na pauta das importações nacionais, a qual demonstra ainda uma forte predominância dos produtos manufaturados.

Dentre os fatores que determinaram as mudanças observadas está o câmbio, sua apreciação é um dos fatores determinantes nos termos de troca, os quais beneficiaram os setores em ascensão, principalmente no estado do Paraná. No entanto a trajetória atual a qual vem se

\footnotetext{
* Mestranda do curso de Desenvolvimento Econômico da UFPR. Integrante da equipe técnica do Boletim de Economia \& Tecnologia . Endereço eletrônico: lacerda.c@ig.com.br

** Doutor em Economia pelo Cedeplar/UFMG. Coordenador do boletim de Economia \& Tecnologia e professor do departamento de economia (DEPECON-UFPR). Endereço eletrônico: luciano.nakabashi@ufpr.br
} 
desenhando principalmente nas mudanças sentidas pela balança comercial brasileira, que após um longo período de superávits inicia um ciclo distinto pode representar um fator não só de estancamento como de retrocesso do mesmo, demonstrando a necessidade de aprofundamento na produção de bens que promovam mais do que isto, que sustentem o crescimento econômico.

A análise conjuntural da relação das importações Brasil e Paraná é tratada na seqüência, acompanhada por uma apresentação detalhada de sua evolução bem como de alguns dos mecanismos determinantes deste processo.

\section{ECONOMIA PARANAENSE}

Pelo Gráfico 1, podemos observar que entre 1996 e 2007 a participação das importações brasileiras de produtos básicos permaneceu praticamente constante, apesar da variação ocorrida entre os dois períodos com uma perda seguida por um ganho de participação relativa. Sua participação passou de $17,8 \%$ para $17,9 \%$, no período.

De qualquer forma, a participação dos produtos manufaturados na pauta de importações brasileira é alta, girando em torno de $80 \%$ no período em questão. Esse valor é alto quando comparado à participação das exportações de manufaturados, que está próximo de 50\%.

\section{GRÁFICO 1 - EVOLUÇÃO DAS IMPORTAÇÕES BRASILEIRAS POR FATOR AGREGADO}

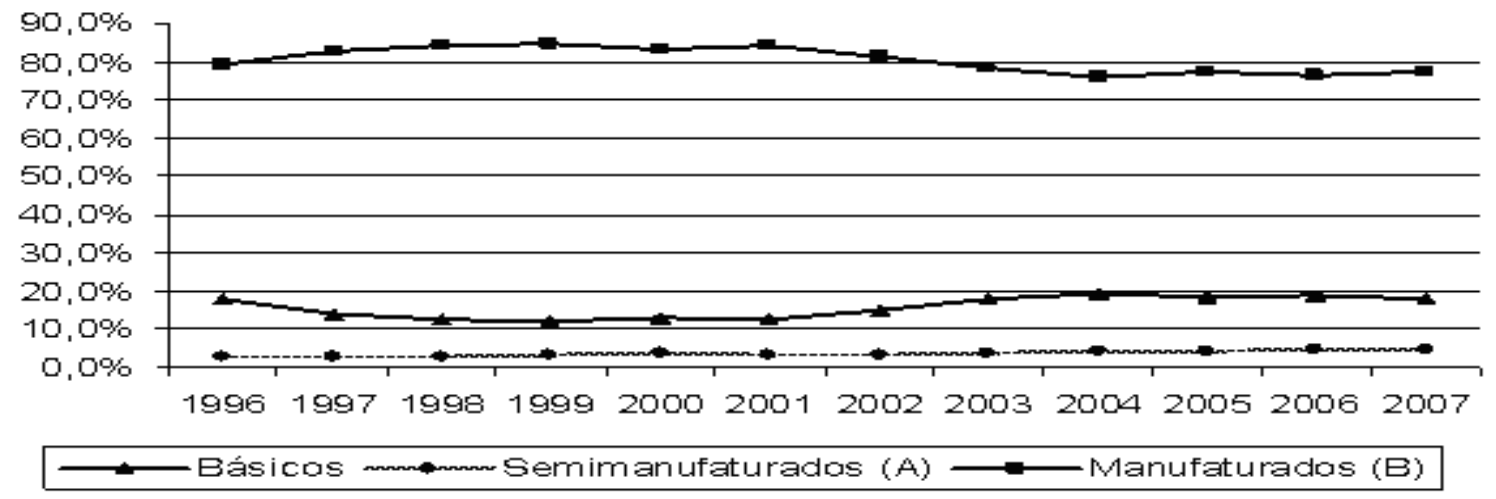

FONTE: SECEX/MDIC - (Elaboração própria)

O problema dessa estrutura diferenciadas nas pautas de exportação e importação é a dinâmica de cada uma delas. Os produtos manufaturados tendem a ter uma maior elasticidade renda. Desse modo, as importações brasileiras tendem a responder mais a variações na renda doméstica em relação às exportações quando ocorrem variações na renda externa. 
Pelo Gráfico 2, podemos constatar que os produtos manufaturados ganharam participação na pauta de importação paranaense no começo do período (1996-1998), mantendo uma participação relativamente constante desde então.

\section{GRÁFICO 2 - EVOLUÇÃO DAS IMPORTAÇÕES PARANAENSES POR FATOR AGREGADO}

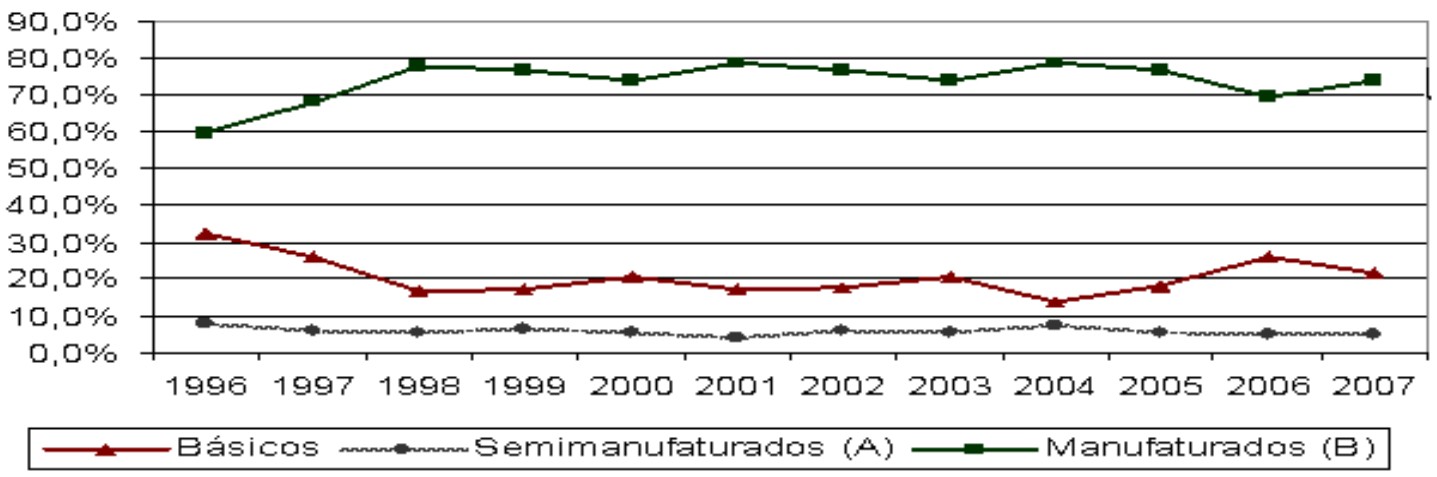

FONTE: SECEX/MDIC - (Elaboração própria)

Assim como para a economia brasileira, a participação das importações de manufaturados na pauta de importações da economia paranaense é alta quando comparada à participação dos manufaturados na pauta de exportações (cerca de 50\%).

Desagregando mais os dados para se ter uma idéia melhor do comportamento das importações brasileiras, para o período de 1999 até julho de 2008, é possível notar que ocorreu um significativo crescimento dos seguintes produtos: óleos brutos de petróleo (4,4\% para 10,5\%); de gasóleo (óleo diesel) ( $0 \%$ para 3\%); gás natural no estado gasoso $(0,02 \%$ para $1,47 \%$ ), naftas para petroquímica ( $0 \%$ para 1,16\%); catodos de cobre refinado/seus elementos, em forma bruta $(0,35 \%$ para $1,26 \%)$; querosene de aviação $(0 \%$ para $0,70 \%)$; e coques de hulha, de linhita ou de turfa $(0,14 \%$ para $0,5 \%)$.

Isso sugere que o Brasil também está ajudando no movimento de alta do preço de algumas commodities. Adicionalmente, indica que o crescimento mais alto da economia brasileira a partir de 2004 tem impulsionado a demanda por insumos energéticos.

TABELA 1 - EVOLUÇÃO DOS 30 PRINCIPAIS PRODUTOS IMPORTADOS PELO BRASIL: 1999-2008

\begin{tabular}{|l|r|r|r|r|r|r|r|r|r|r|}
\hline \multicolumn{1}{|c|}{ BRASIL } & $\mathbf{1 9 9 9}$ & $\mathbf{2 0 0 0}$ & $\mathbf{2 0 0 1}$ & $\mathbf{2 0 0 2}$ & $\mathbf{2 0 0 3}$ & $\mathbf{2 0 0 4}$ & $\mathbf{2 0 0 5}$ & $\mathbf{2 0 0 6}$ & $\mathbf{2 0 0 7}$ & $\mathbf{2 0 0 8}$ \\
\hline Óleos brutos de petróleo & 4,40 & 5,71 & 5,74 & 6,87 & 7,87 & 10,78 & 10,42 & 9,94 & 9,94 & 10,50 \\
\hline "Gasoleo" (óleo diesel) & 0,00 & 0,00 & 0,00 & 2,25 & 1,64 & 1,32 & 1,39 & 1,91 & 2,50 & 2,97 \\
\hline Outros cloreto de potássio & 0,84 & 1,00 & 0,93 & 1,11 & 1,29 & 1,55 & 1,30 & 1,04 & 1,24 & 1,85 \\
\hline $\begin{array}{l}\text { Automóveis c/motor } \\
\text { explosão,1500<CM3<=3000, até }\end{array}$ & 1,65 & 1,45 & 1,43 & 0,99 & 0,84 & 0,66 & 0,67 & 1,48 & 1,68 & 1,78 \\
\hline
\end{tabular}




\begin{tabular}{|c|c|c|c|c|c|c|c|c|c|c|}
\hline 6 passageiros & & & & & & & & & & \\
\hline Gás natural no estado gasoso & 0,02 & 0,20 & 0,38 & 0,78 & 0,89 & 0,93 & 1,10 & 1,44 & 1,24 & 1,47 \\
\hline $\begin{array}{l}\text { Trigo ( Exc. Trigo duro ou p/ } \\
\text { semeadura), e trigo c/ centeio }\end{array}$ & 1,68 & 1,53 & 1,56 & 1,85 & 2,08 & 1,16 & 0,88 & 1,08 & 1,15 & 1,28 \\
\hline $\begin{array}{l}\text { Catodos de cobre refinados/seus } \\
\text { elementos, em forma bruta }\end{array}$ & 0,35 & 0,51 & 0,41 & 0,33 & 0,54 & 0,67 & 0,81 & 1,31 & 1,34 & 1,26 \\
\hline Naftas para petroquímica & 0,00 & 0,00 & 0,00 & 0,97 & 1,21 & 1,33 & 1,87 & 1,89 & 1,56 & 1,16 \\
\hline $\begin{array}{l}\text { Dispositivos de cristais líquidos } \\
\text { (LCD) }\end{array}$ & 0,14 & 0,22 & 0,14 & 0,22 & 0,39 & 0,53 & 0,75 & 0,86 & 0,94 & 1,03 \\
\hline $\begin{array}{l}\text { Outras hulhas, mesmo em pó, } \\
\text { mas não aglomeradas }\end{array}$ & 0,82 & 0,71 & 0,79 & 1,01 & 1,03 & 1,05 & 1,38 & 1,24 & 0,99 & 0,96 \\
\hline $\begin{array}{l}\text { Outras partes. p/apar.d./telefonia } \\
\text { /telegrafia }\end{array}$ & 0,00 & 0,00 & 0,00 & 0,00 & 0,00 & 0,00 & 0,00 & 0,00 & 1,04 & 0,94 \\
\hline $\begin{array}{l}\text { Outras partes p/ avião ou } \\
\text { helicópteros }\end{array}$ & 1,01 & 1,12 & 1,24 & 1,01 & 1,02 & 1,21 & 1,07 & 1,03 & 1,03 & 0,93 \\
\hline $\begin{array}{l}\text { Outras partes e acess.p/tratores e } \\
\text { veículos automotivos }\end{array}$ & 1,09 & 1,16 & 1,04 & 1,00 & 1,08 & 1,08 & 1,16 & 0,91 & 0,84 & 0,76 \\
\hline $\begin{array}{l}\text { Diidrogênio-ortofosfato de } \\
\text { amônio, incl. Mist. Hidrog.etc. }\end{array}$ & 0,35 & 0,37 & 0,43 & 0,48 & 0,70 & 0,79 & 0,44 & 0,34 & 0,56 & 0,74 \\
\hline $\begin{array}{l}\text { Outras partes } \mathrm{p} / \text { ap. receptores. } \\
\text { Radiodif.televisão, etc. }\end{array}$ & 0,33 & 0,49 & 0,40 & 0,37 & 0,37 & 0,42 & 0,35 & 0,58 & 0,54 & 0,73 \\
\hline Querosenes de avião & 0,00 & 0,00 & 0,00 & 0,36 & 0,15 & 0,06 & 0,22 & 0,41 & 0,44 & 0,70 \\
\hline Sulfetos de Minério de cobre & 0,45 & 0,46 & 0,40 & 0,41 & 0,45 & 0,75 & 0,63 & 1,14 & 0,88 & 0,68 \\
\hline $\begin{array}{l}\text { Uréioa com teor de nitrogénio } \\
>45 \% \text { em peso }\end{array}$ & 0,16 & 0,32 & 0,20 & 0,25 & 0,51 & 0,56 & 0,48 & 0,40 & 0,64 & 0,68 \\
\hline $\begin{array}{l}\text { Superfosfato, teor } \mathrm{rde} \\
\text { pentoxidos de fósforo } \\
\text { (P2O5) }>45 \%\end{array}$ & 0,08 & 0,12 & 0,10 & 0,15 & 0,26 & 0,32 & 0,21 & 0,20 & 0,32 & 0,60 \\
\hline $\begin{array}{l}\text { Caixas de marcha p/ veículos } \\
\text { automóveis }\end{array}$ & 0,41 & 0,41 & 0,35 & 0,37 & 0,42 & 0,54 & 0,57 & 0,48 & 0,57 & 0,60 \\
\hline $\begin{array}{l}\text { Turborreatores de empuxo } \\
>25 \mathrm{KN}\end{array}$ & 0,73 & 0,87 & 1,18 & 0,86 & 0,82 & 0,82 & 0,75 & 0,73 & 0,65 & 0,60 \\
\hline $\begin{array}{l}\text { Outros circuitos integrados } \\
\text { monopolísticos }\end{array}$ & 0,00 & 0,00 & 0,00 & 0,00 & 0,00 & 0,00 & 0,00 & 0,00 & 0,58 & 0,56 \\
\hline $\begin{array}{l}\text { Outras partes de acess. De } \\
\text { carroceria para veículos } \\
\text { automóveis }\end{array}$ & 0,44 & 0,47 & 0,50 & 0,60 & 0,56 & 0,56 & 0,54 & 0,45 & 0,50 & 0,56 \\
\hline $\begin{array}{l}\text { Partes de turborreatoes oude } \\
\text { turbopropulsores }\end{array}$ & 0,44 & 0,46 & 0,50 & 0,26 & 0,22 & 0,44 & 0,55 & 0,53 & 0,56 & 0,51 \\
\hline $\begin{array}{l}\text { Microprocessadores mont. } \\
\text { p/superf. (SMD) }\end{array}$ & 0,00 & 0,00 & 0,00 & 0,00 & 0,00 & 0,00 & 0,00 & 0,00 & 0,56 & 0,50 \\
\hline $\begin{array}{l}\text { Coques de Hulha de linhita ou de } \\
\text { turfa }\end{array}$ & 0,14 & 0,20 & 0,25 & 0,34 & 0,63 & 0,85 & 0,47 & 0,28 & 0,26 & 0,50 \\
\hline $\begin{array}{l}\text { Outros veículos automóveis com } \\
\text { motor diesel, } \mathrm{p} / \text { carga }<=5 \mathrm{~T}\end{array}$ & 0,61 & 0,72 & 0,72 & 0,49 & 0,35 & 0,33 & 0,56 & 0,59 & 0,54 & 0,49 \\
\hline $\begin{array}{l}\text { Enxofre a granel, exc. } \\
\text { Sublimmado, precipitado ou } \\
\text { coloidal }\end{array}$ & 0,11 & 0,14 & 0,08 & 0,10 & 0,21 & 0,21 & 0,15 & 0,11 & 0,14 & 0,47 \\
\hline Outros circuitos integrados & 0,00 & 0,00 & 0,00 & 0,00 & 0,00 & 0,00 & 0,00 & 0,00 & 0,46 & 0,42 \\
\hline $\begin{array}{l}\text { Outras máquinas e aparelhos } \\
\text { mecânicos c/ função própria }\end{array}$ & 1,01 & 0,79 & 0,65 & 0,50 & 0,47 & 0,48 & 0,42 & 0,37 & 0,32 & 0,40 \\
\hline $\begin{array}{l}\text { Total dos principais produtos } \\
\text { importados }\end{array}$ & 17,26 & 19,42 & 19,43 & 23,90 & 26,00 & 29,38 & 29,14 & 30,75 & 34,03 & 36,62 \\
\hline
\end{tabular}

FONTE: SECEX/MDIC - (Elaboração própria) NOTA: dados 2008 até junho. Os 30 principais prod. são classif. de acordo com sua ordem de import. em 2008

A elevação nas importações dos seguintes itens: de uréia com teor de nitrogênio > 45\% em peso (0,16\% para 0,68\%); superfosfato, teor de pentóxido de fósforo (p2o5) > 45\% (0,08\% 
para $0,6 \%$ ); e de enxofre a granel, exc.sublimado, precipitado ou coloidal (de $0,11 \%$ para $0,47 \%$ ) indicam o bom desempenho do setor agropecuário brasileiro nos últimos anos.

Assim, apesar da elevada participação de produtos manufaturados na pauta de importações do Brasil, o crescimento de boa parte dos produtos importados de insumos destinados à produção, ou seja, essa elevação é um reflexo do crescimento da economia.

Fazendo a análise de dados similares, mas para o caso paranaense, pelos dados da Tabela 2, percebemos a grande elevação relativa das importações de óleos brutos de petróleo, entre 1999 e 2008. Em 2008, um quarto das exportações paranaenses era desse produto.

A elevação da participação dos seguintes produtos: outros cloretos de potássio $(3,19 \%$ para 4,39\%); superfosfato, teor de pentoxido de fósforo ( 2205$)>45 \%(0,22 \%$ para 2,57\%); diidrogeno-ortofosfato de amônio, incl. mist. hidrogen. Etc (1,65\% para 1,94\%); hidrogenoortofosfato de diamonio, teor arsênio $>=6 \mathrm{mg} / \mathrm{kg}(0,09 \%$ para 1,68\%); outs. adubos/fertiliz. miner. quim. c/ nitrogênio e fósforo ( $0 \%$ para $1 \%)$; sulfato de amônio $(0,47 \%$ para $0,68 \%$ ); e adubos ou fertilizantes c/nitrogênio, fósforo e potássio ( $0 \%$ para 0,52\%); entre 1999 e 2008, refletem o crescimento do setor agrícola no estado. $O$ crescimento destes na pauta de importações do estado é bem maior quando comparado com o Brasil devido à importância da agropecuária no Paraná.

TABELA 2 - EVOLUÇÃO DOS 30 PRINCIPAIS PRODUTOS IMPORTADOS PELO PARANÁ: 1999- 2008

\begin{tabular}{|l|r|r|r|r|r|r|r|r|c|c|}
\hline PARANÁ & $\mathbf{1 9 9 9}$ & $\mathbf{2 0 0 0}$ & $\mathbf{2 0 0 1}$ & $\mathbf{2 0 0 2}$ & $\mathbf{2 0 0 3}$ & $\mathbf{2 0 0 4}$ & $\mathbf{2 0 0 5}$ & $\mathbf{2 0 0 6}$ & $\mathbf{2 0 0 7}$ & $\mathbf{2 0 0 8}$ \\
\hline Óleos brutos de petróleo & 8,42 & 13,00 & 11,54 & 8,87 & 9,88 & 8,20 & 12,69 & 21,97 & 18,61 & 24,59 \\
\hline $\begin{array}{l}\text { Autom c/ motor explosão, } \\
\text { 1500<CM3<=3000, até 6 passag }\end{array}$ & 9,39 & 4,51 & 4,07 & 1,50 & 0,81 & 0,87 & 0,70 & 5,40 & 7,48 & 5,73 \\
\hline Outros cloretos de potássio & 3,19 & 3,22 & 2,38 & 3,76 & 3,96 & 5,36 & 3,27 & 3,08 & 2,93 & 4,39 \\
\hline $\begin{array}{l}\text { Superfosfato teor de pentoxido de } \\
\text { fósforo (P2O5)>45\% }\end{array}$ & 0,22 & 0,64 & 0,58 & 0,74 & 1,30 & 1,73 & 0,86 & 0,63 & 1,26 & 2,57 \\
\hline $\begin{array}{l}\text { Diidrogenio ortofosfato de amônio, } \\
\text { incl mist. Hidrogen etc. }\end{array}$ & 1,65 & 1,48 & 1,68 & 1,82 & 2,64 & 3,40 & 1,17 & 0,89 & 1,61 & 1,94 \\
\hline $\begin{array}{l}\text { Hidrog ortosfofato de diamonio de } \\
\text { diamonio teor, arsênio>=6MG/KG }\end{array}$ & 0,09 & 0,24 & 0,17 & 0,30 & 0,40 & 0,68 & 0,48 & 0,30 & 1,09 & 1,68 \\
\hline $\begin{array}{l}\text { Outras partes e acess. De carroçaria } \\
\text { p/ veic. Automóveis. }\end{array}$ & 2,06 & 2,57 & 2,84 & 3,61 & 3,46 & 3,02 & 2,53 & 1,90 & 1,88 & 1,54 \\
\hline Uréia c/ teor de nitr >45\% em peso & 0,27 & 0,76 & 0,34 & 0,46 & 1,03 & 1,22 & 0,85 & 0,71 & 0,95 & 1,47 \\
\hline Outros circuitos integrados & 0,00 & 0,00 & 0,00 & 0,00 & 0,00 & 0,00 & 0,00 & 0,00 & 1,77 & 1,35 \\
\hline $\begin{array}{l}\text { Trigo (exc. Trigo duro ou } \\
\text { p/semeadura), e trigo c/centeio }\end{array}$ & 1,69 & 1,40 & 1,05 & 1,48 & 1,97 & 0,56 & 0,56 & 0,88 & 0,79 & 1,19 \\
\hline Caixas de marchas p/ veíc autom & 0,91 & 1,51 & 1,76 & 2,18 & 1,90 & 1,89 & 2,29 & 1,69 & 1,49 & 1,17 \\
\hline $\begin{array}{l}\text { Outras partes e acess. p/ tratos e } \\
\text { veículos automóveis }\end{array}$ & 2,72 & 3,50 & 2,60 & 2,86 & 2,90 & 2,51 & 2,74 & 1,72 & 1,55 & 1,17 \\
\hline Outros ad quim.c/nitrog e fósf & 0,00 & 0,02 & 0,07 & 0,43 & 0,86 & 1,11 & 0,57 & 0,55 & 0,81 & 1,00 \\
\hline
\end{tabular}




\begin{tabular}{|c|c|c|c|c|c|c|c|c|c|c|}
\hline $\begin{array}{l}\text { automóveis c/motor } \\
\text { explosão,cil<=1000CM3 }\end{array}$ & 1,22 & 0,55 & 0,65 & 0,23 & 0,08 & 0,01 & 0,00 & 0,00 & 0,68 & 0,86 \\
\hline Metanol (álcool metílico) & 0,16 & 0,29 & 0,31 & 0,61 & 0,83 & 0,78 & 0,67 & 0,67 & 0,65 & 0,75 \\
\hline sulfato de amônio & 0,47 & 0,61 & 0,72 & 0,60 & 0,79 & 1,11 & 0,49 & 0,57 & 0,66 & 0,68 \\
\hline Malte não torrado, int ou partido & 0,44 & 0,43 & 0,50 & 0,72 & 0,19 & 0,31 & 0,16 & 0,27 & 0,62 & 0,60 \\
\hline $\begin{array}{l}\text { Tela } \mathrm{p} / \text { microcomputadores } \\
\text { portáteis, policromática }\end{array}$ & 0,00 & 0,00 & 0,00 & 0,00 & 0,00 & 0,00 & 0,00 & 0,14 & 0,49 & 0,59 \\
\hline Unid de discos mag, $\mathrm{p} /$ disc rígidos & 0,09 & 0,04 & 0,05 & 0,06 & 0,02 & 0,11 & 0,39 & 0,60 & 0,75 & 0,56 \\
\hline $\begin{array}{l}\text { Outros veículos automóveis c/ } \\
\text { motor diesel, } \mathrm{p} / \text { carga }<=5 \mathrm{~T}\end{array}$ & 0,00 & 0,00 & 0,41 & 0,07 & 0,00 & 0,00 & 0,00 & 0,04 & 0,56 & 0,56 \\
\hline $\begin{array}{l}\text { Adubos e fertilizantes, fósforo e } \\
\text { potássio }\end{array}$ & 0,00 & 0,00 & 0,00 & 0,00 & 0,03 & 0,02 & 0,00 & 0,00 & 0,10 & 0,52 \\
\hline $\begin{array}{l}\text { Outros motores de explosão, p/ } \\
\text { veículos Cap.87,Sup.1000CM3 }\end{array}$ & 0,99 & 1,69 & 1,48 & 2,12 & 1,44 & 0,61 & 1,81 & 0,75 & 0,68 & 0,45 \\
\hline Farinha de trigo & 0,13 & 0,10 & 0,13 & 0,15 & 0,01 & 0,03 & 0,03 & 0,15 & 0,42 & 0,43 \\
\hline $\begin{array}{l}\text { Milho em grão exceto para } \\
\text { semeadura }\end{array}$ & 0,31 & 0,23 & 0,41 & 0,32 & 0,56 & 0,33 & 0,49 & 0,59 & 0,82 & 0,42 \\
\hline $\begin{array}{l}\text { Acido fosfonometiliminiduacetuci e } \\
\text { AC. Trimetilfosonico }\end{array}$ & 0,00 & 0,00 & 0,00 & 0,00 & 0,12 & 0,33 & 0,12 & 0,06 & 0,24 & 0,41 \\
\hline $\begin{array}{l}\text { Injetores para motores diesel ou } \\
\text { semidiesel }\end{array}$ & 0,05 & 0,09 & 0,12 & 0,24 & 0,32 & 0,44 & 0,48 & 0,61 & 0,63 & 0,40 \\
\hline $\begin{array}{l}\text { Outs.compostos heterocicl.c/1 ciclo } \\
\text { pirazo, } \mathrm{n} / \text { condensado }\end{array}$ & 0,00 & 0,00 & 0,00 & 0,61 & 0,00 & 0,00 & 0,00 & 0,00 & 0,47 & 0,40 \\
\hline outs.partes de bombas p/líquido & 0,00 & 0,00 & 0,00 & 0,00 & 0,00 & 0,00 & 0,00 & 0,66 & 0,50 & 0,38 \\
\hline Outras unidades de discos ópticos & 0,01 & 0,02 & 0,01 & 0,01 & 0,01 & 0,07 & 0,16 & 0,33 & 0,44 & 0,36 \\
\hline "gasóleo" (óleo diesel) & 0,00 & 0,00 & 0,00 & 0,62 & 0,38 & 1,61 & 0,00 & 0,57 & 0,53 & 0,33 \\
\hline Óleos brutos de petróleo & 8,42 & 13,00 & 11,54 & 8,87 & 9,88 & 8,20 & 12,69 & 21,97 & 18,61 & 24,59 \\
\hline
\end{tabular}

FONTE: SECEX/MDIC - (Elaboração própria)

NOTA: os dados 2008 são até junho. Os 30 principais produtos são classificados de acordo com sua ordem de importância em 2008

Por outro lado, as importações estão menos dependentes de automóveis e seus componentes. É notória a queda de participação de automóveis c/motor explosão, $1500<\mathrm{cm} 3<=3000$, ate 6 passageiros, que passou de 9,39\% para 5,73\%, no período. Outros exemplos são: outras partes e acessórios de carrocerias p/ veículos automóveis (2,06\% para 1,54\%); automóveis c/motor explosão, cil $<=1000 \mathrm{~cm} 3(1,22 \%$ para $0,86 \%)$; e outros motores de explosão, p/ veículos cap.87, sup.1000CM3 (0,99\% para 0,45\%).

Assim como no Brasil, os produtos que estão ganhando participação na pauta de exportação do Paraná refletem o crescimento econômico do estado, ou seja, o aumento das importações é positivo no sentido de fornecer os insumos necessários para o crescimento das atividades produtivas no estado.

Mesmo com esse aspecto positivo do aumento das importações mencionado acima, é importante ressaltar que a elevada taxa de crescimento das importações está se tornando um problema na medida em que os déficits em conta corrente estão aumentando de forma acelerada, 
conforme pode ser observado pelos déficits apresentados nas transações correntes em todos os meses de 2008 (Tabela 3).

TABELA 3 - EVOLUÇÃO DO SALDO DAS TRANSAÇÕES CORRENTO NO BRASIL EM 2008

\begin{tabular}{|c|c|c|c|}
\hline & \multirow[b]{2}{*}{ PERÍODO } & \multicolumn{2}{|c|}{ TRANSAÇÕES CORRENTES } \\
\hline & & $\begin{array}{c}\text { SALDO TRANSAÇÕES } \\
\text { CORRENTES }^{1}\end{array}$ & $\begin{array}{c}\text { PERCENTUAL DO PIB EM } 12 \\
\text { MESES }\end{array}$ \\
\hline \multirow{7}{*}{2008} & Jan. & -4.232 & $-0,18$ \\
\hline & Fev. & -2.090 & $-0,37$ \\
\hline & Mar. & -4.429 & $-0,71$ \\
\hline & Abr. & -3.310 & $-1,08$ \\
\hline & Maio & -649 & $-1,1$ \\
\hline & Jun. & -2.596 & $-1,32$ \\
\hline & Jul. & -2.111 & $-1,41$ \\
\hline
\end{tabular}

FONTE: BACEN

NOTA (1): em US\$ milhões

Ainda pelo Gráfico 3, nota-se uma elevada taxa de crescimento das importações brasileiras e paranaenses, principalmente a partir de 2004.

GRÁFICO 3 - EVOLUÇÃO DA TAXA DE VARIAÇÃO DAS IMPORTAÇÕES: BRASIL E PARANÁ (US\$ 1.000 FOB) $-1998-2008$

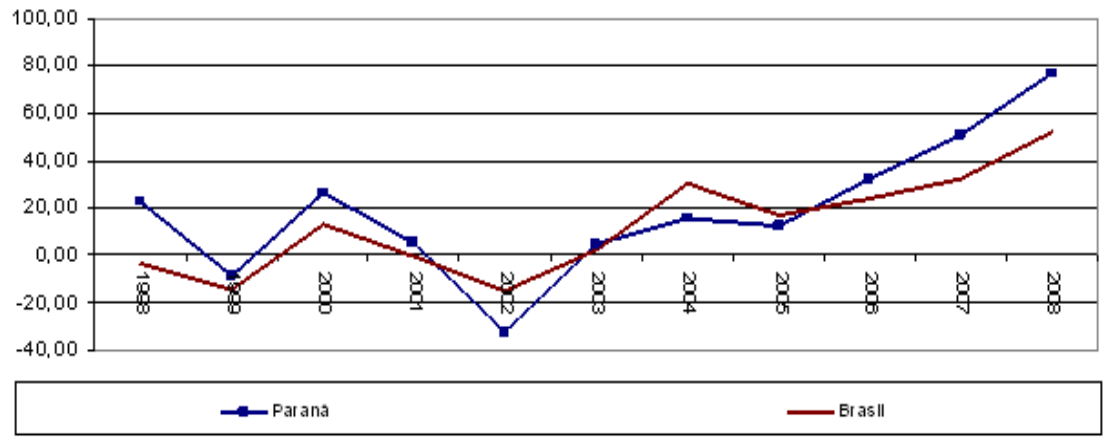

FONTE: SECEX/MDIC.

NOTA: a comparação para 2008 se refere ao primeiro semestre.

Os efeitos sobre as importações brasileiras não são de um aumento relativo da participação de bens de capital, que perdeu participação (de 35\% para próximo de 25\%), como tem sido relatado por vários analistas. Como visto anteriormente, o maior impacto tem sido no ganho de participação relativa no segmento de combustíveis e lubrificantes, passando de 10,94\% para 19,89\%, no período, de acordo com os dados do Gráfico 4. 
GRÁFICO 4 - EVOLUÇÃO DA PARTICIPAÇÃO DAS IMPORTAÇÕES BRASILEIRAS POR DAS CONTAS NACIONAIS: $1999-2008$.

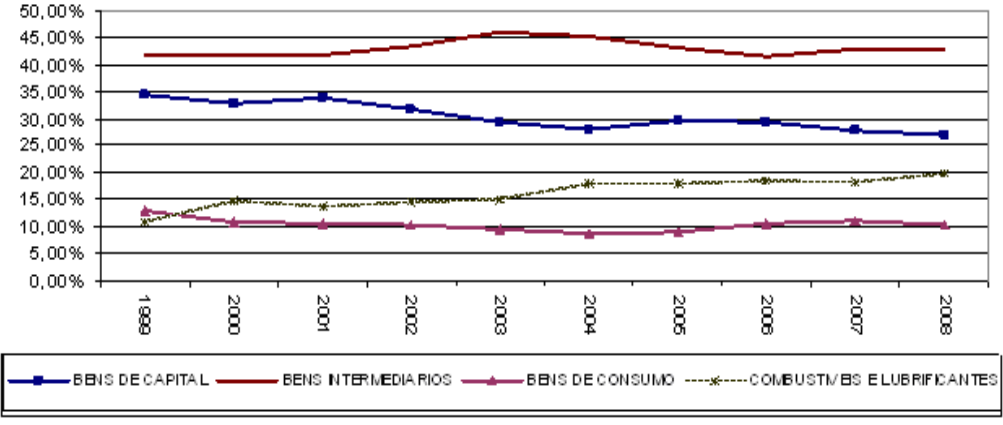

FONTE: SECEX/MDIC.

NOTA: a comparação para 2008 se refere ao primeiro semestre.

No estado paranaense, os efeitos são semelhantes, ou seja, com perda de participação dos bens de capital (de 29,16\% para 18,04\%) e ganho de participação dos combustíveis e lubrificantes, com esta passando de 9,37\% para 25,11\%, de acordo com os dados do Gráfico 5.

GRÁFICO 5.- EVOLUÇÃO DA PARTICIPAÇÃO DAS IMPORTAÇÕES PARANAENSES POR SETORES DAS CONTAS NACIONAIS: 1999-2008.

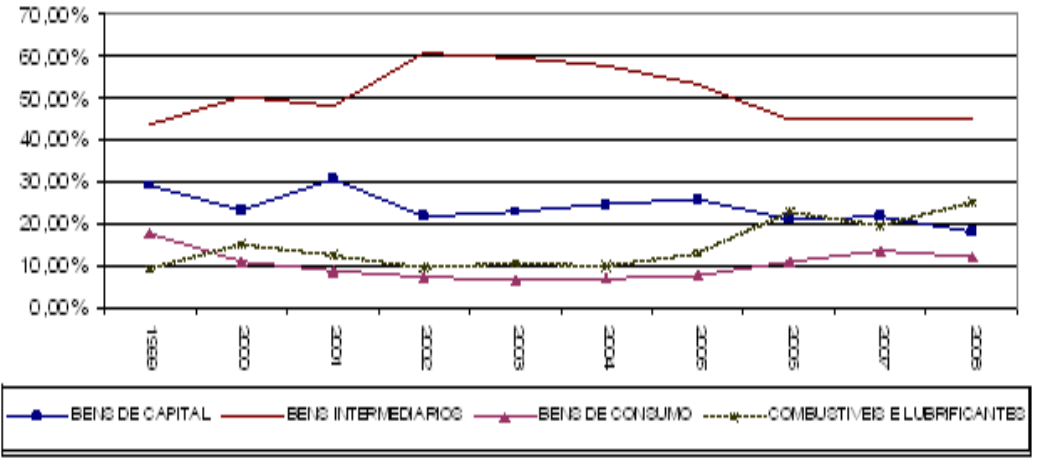

FONTE: SECEX/MDIC.

NOTA: a comparação para 2008 se refere ao primeiro semestre.

Assim, pelo exposto acima, a elevação das importações tem como uma de suas causas o aumento da atividade produtiva no Brasil e no Paraná. No entanto, não podemos nos esquecer do papel do câmbio, que está estimulando demasiadamente a elevação das importações com impactos negativos sobre a conta corrente, o que levará, possivelmente, a problemas nas restrições externas do crescimento das economias brasileira e paranaense, com impactos negativos sobre seus respectivos crescimentos, no médio prazo. A apreciação do câmbio em termos nominais dos últimos três anos (2006-2008) ficou em torno de 30\%, o que corresponde uma média de, aproximadamente, $10 \%$ a.a. 
TABELA 4 - EVOLUÇÃO DATA TAXA DE CÂMBIO: BRASIL 1998 - 2008

\begin{tabular}{c|c}
\hline ANO & TAXA \\
\hline 1998 & 1,1597 \\
1999 & 1,8139 \\
2000 & 1,8294 \\
2001 & 2,3496 \\
2002 & 2,9204 \\
2003 & 3,0775 \\
2004 & 2,9251 \\
2005 & 2,4344 \\
2006 & 2,1753 \\
2007 & 1,9471 \\
$2008 *$ & 1,6719 \\
\hline
\end{tabular}

FONTE: IPEADATA

NOTA: Referente à média de Jan. a Ago.

Outro elemento importante que deve ser considerado na análise é a evolução da importação de bens de capital. De acordo com os dados apresentados nos Gráficos 4 e 5, não está ocorrendo uma elevação na participação dos bens de capital na pauta de importações do Brasil e do Paraná, o que poderia gerar um estímulo na ampliação da capacidade produtiva em ambas as regiões com efeitos positivos sobre o crescimento futuro.

\section{CONCLUSÕES}

As alterações da pauta das importações do Brasil e do Estado do Paraná tendem a refletir o crescimento de ambas as economias. Se por um lado as importações brasileiras registram uma elevação do quantum de insumos energéticos ainda que com a manutenção do montante das manufaturas exportadas a qual na última década ficou em torno de $80 \%$ contra os 50\% das exportações, por outro o estado do Paraná, registra uma maior diversificação de sua pauta de importações, com a redução de bens como os automóveis, todavia com o aprofundamento de insumos ligados ao setor agropecuários, o qual é o motor das suas exportações.

É notável o papel que o câmbio exerceu neste processo, sua apreciação é fator determinante no crescimento de produção de alguns bens, leiam-se as commodities, as quais foram fortemente beneficiadas pelas alterações na última década dos termos de troca que nortearam o rumo das relações comerciais entre o Brasil e seus principais parceiros, bem como para o Paraná. A perspectiva das mudanças que demonstram os movimentos das importações ligadas ao crescimento do produto é bastante positiva, quando comparada a períodos 
relativamente recentes da história econômica brasileira onde as mesmas foram utilizadas apenas no atendimento da demanda de bens ligada a necessidades não menos importantes, porém altamente custosas, dado o seu direcionamento. No entanto as armadilhas que se formam nesta relação devem ser cuidadosamente tratadas, pois são pontos de estrangulamento deste processo.

A primeira trata das elasticidades renda dos bens transacionados, as quais tendem a beneficiar em maior escala os bens com maior valor agregado. E a segunda, mais eminente, está ligada as recentes alterações da balança comercial, as quais derivam em parte do próprio processo de apreciação, tornando notável a necessidade de avanço no aprofundamento de processos como o do setor automotivo da indústria paranaense, para que não se corra o risco de cair novamente na armadilha da instabilidade comercial que sustenta a negociação das commodities. Ou seja, devem ser aproveitadas as condições positivas que se formam para alguns bens, no entanto, as mesmas devem ser utilizadas para erodir as armadilhas que advém destas mesmas condições.

\section{REFERÊNCIAS}

Banco Central do Brasil (BACEN). Série histórica do Balanço de Pagamentos. Disponível em: <www.bcb.gov.br>. Acesso em: 02/09/08.

IPEADATA. Série histórica do Câmbio. Disponível em: <www.ipeadata.gov.br>. Acesso em: 02/09/08.

MDIC/SECEX. Estatística da Exportações por Unidade da Federação. Disponível em: < http://www.desenvolvimento.gov.br >. Acesso em: 02/09/08. 